All that Miss Bird tells us of her visit to the Ainos is well worth quoting ; but we have space for only one more quotation, and that with reference to their physique :-

"After the yellow skins, the stiff horse hair, the feeble eyelids, the elongated eyes, the sloping eyebrows, the flat noses, the sunken chests, the Mongolian features, the puny physique, the shaky walk of the men, the restricted totter of the women, and the general impression of degeneracy conveyed by the appearance of the Japanese, the Ainos make a very singular impression. All but two or three that I have seen are the most ferocious-looking of savages, with a physique vigorous enough for carrying out the most ferocious intentions, but as soon as they speak the countenance brightens into a smile as gentle as that of a woman, something which can never be forgotten. The men are about the middle height, broadchested, broad-shouldered, 'thick-set,' very strongly built, the arms and legs short, thick, and muscular, the hands and feet large. The bodies, and specially the limbs, of many are covered with short bristly hair. I have seen two boys whose backs are covered with fur as fine and soft as that of a cat. The heads and faces are very striking. The foreheads are very high, broad, and prominent, and at first sight give one the impression of an unusual capacity for intellectual development; the ears are small and set low ; the noses are straight, but short, and broad at the nostrils; the mouths are wide, but well formed; and the lips rarely show a tendency to fulness. The neck is short, the cranium rounded, the cheek-bones low, and the lower part of the face is small as compared with the upper, the peculiarity called a 'jowl' being unknown. The eyebrows are full, and form a straight line nearly across the face. The eyes are large, tolerably deeply set, and very beautiful, the colour a rich liquid brown, the expression singularly soft, and the eyelashes long, silky, and abundant. The skin has the Italian olive tint, but in most cases is thin, and light enough to show the changes of colour in the cheek. The teeth are small, regular, and very white; the incisors and 'eye teeth' are not disproportionately large, as is usually the case among the Japanese; there is no tendency towards prognathism; and the fold of integument which conceals the upper eyelids of the Japanese is never to be met with. The features, expression, and aspect are European rather than Asiatic.

"The 'ferocious savagery' of the appearance of the men is produced by a profusion of thick soft black hair, divided in the middle, and falling in heavy masses nearly to the shoulders. Out of doors it is kept from falling over the face by a fillet round the brow. The beards are equally profuse, quite magnificent, and generally wavy, and in the case of the old men they give a truly patriarchal and venerable aspect, in spite of the yellow tinge produced by smoke and want of cleanliness. The savage look produced by the masses of hair and beard, and the thick eyebrows, is mitigated by the softness in the dreamy brown eyes, and is altogether obliterated by the exceeding sweetness of the smile, which belongs in greater or less degree to all the rougher sex.

"I have measured the height of thirty of the adult men of this village, and it ranges from 5 feet 4 inches to 5 feet $6 \frac{1}{2}$ inches. The circumference of the heads averages $22^{\prime} \mathrm{I}$ inches, and the arc, from ear to ear, 13 inches. According to Mr. Davies the average weight of the Aino adult masculine brain, ascertained by measurement of Aino skulls, is $45^{\circ} 90$ ounces avoirdupois, a brain weight said to exceed that of all the races, Hindoo and Mussulman, on the Indian plains, and that of the aboriginal races of India and Ceylon, and is only paralleled by that of the races of the Himalayas, the Siamese, and the Chinese Burmese. Mr. Davies says, further, that it exceeds the mean brain weight of Asiatic races in general. Yet with all this the Ainos are a stupid people !"

The coast Ainos, Miss Bird tells us, she found had more hair on their bodies than those in the interior, and in some other respects differed in appearance, a difference probably to be accounted for by their mode of life and their surroundings. The Aino garments are often exceedingly handsome, being decorated with "geometrical" patterns in which the Greek fret takes part, in coarse blue cotton, braided most dexterously with scarlet and white thread. The modesty of the women is very remarkable, sometimes almost excessive even to European notions; nor do they seem to be the unmitigated drudges that most savage women are. The great hero of the Ainos is Yoshitsuné, who is also the most popular hero of Japanese history; the Ainos worship him, and Miss Bird was permitted to visit his shrine on a hill near Biratori, the Aino village at which she spent most of her time. He lived in the twelfth century, and was the brother of the Shôgun of the time, whose jealousy, according to some, compelled him to take refuge in Yezo. "None believe this more firmly than the Ainos themselves, who assert that he taught their fathers the arts of civilisation, with letters and numbers, and gave them righteous laws, and he is worshipped by many of them under a name which signifies Master of the Law. I have been told by old men in Biratori, Usu, and Lebungé, that a later Japanese conqueror carried away the books in which the arts were written, and that since his time the arts themselves have been lost, and the Ainos have fallen into their present condition! On asking why the Ainos do not make vessels of iron and clay as well as knives and spears, the invariable answer is, 'The Japanese took away the books.'" This, combined with some other things which Miss Bird tells us of these Ainos, makes it seem quite possible that they are now a degenerate remnant of a people who formerly were comparatively cultured, and who may possibly have had "books" which the Japanese, their conquerors and masters, "took away." These strange people are certainly worthy of further study. The illustrations we are able to give, by the kindness of Mr. Murray, will give the reader some idea of their appearance and habits. We strongly recommend the reader to go to Miss Bird's volumes for further information of what she saw and heard while sojourning among them.

Again we commend these two works to all who desire to get, in comparatively short space, a very complete view of the past history and present condition of Japan.

\section{BELL'S PHOTOPHONE}

$\mathrm{BY}$ the courtesy of Prof. Graham Bell we are at length able to do somewhat ampler justice to his latest discovery than has hitherto been possible. He has supplied us with certain details not hitherto published, and has also furnished us with drawings of his apparatus and experiments. Prof. Bell is at present in Paris, and, as was mentioned in our columns last week, has there repeated some of his experiments.

Our readers are already aware that the object of the photophone is the transmission of sounds both musical and vocal to a distance by the agency of a beam of light of varying intensity; and that the first successful attempts made by Prof. Bell and his co-labourer, Mr. Sumner Tainter, were based upon the known property of the element selenium, the electric resistance of which varies with the degree of illumination to which it is exposed. Hence, given a transmitting instrument such as a flexible mirror by which the vibrations of a sound could throw into vibration a beam of light, a receiver consisting of sensitive selenium forming part of an electric circuit with a battery and a telephone should suffice to translate the varying intensities of light into corresponding varying intensities of electric current, and finally into vibrations of the telephone disk audible once more as sound. This funda- 
mental conception dates from 1878, when in lecturing before the Royal Institution Prof. Bell announced the possibility of hearing a shadow fall upon a piece of selenium included in a telephone circuit. The photo- phone, however, outgrew the particular electrical combination that suggested it ; for not the least of the remarkable points in this research is the discovery that audible vibrations are set up in thin disks of almost every kind of

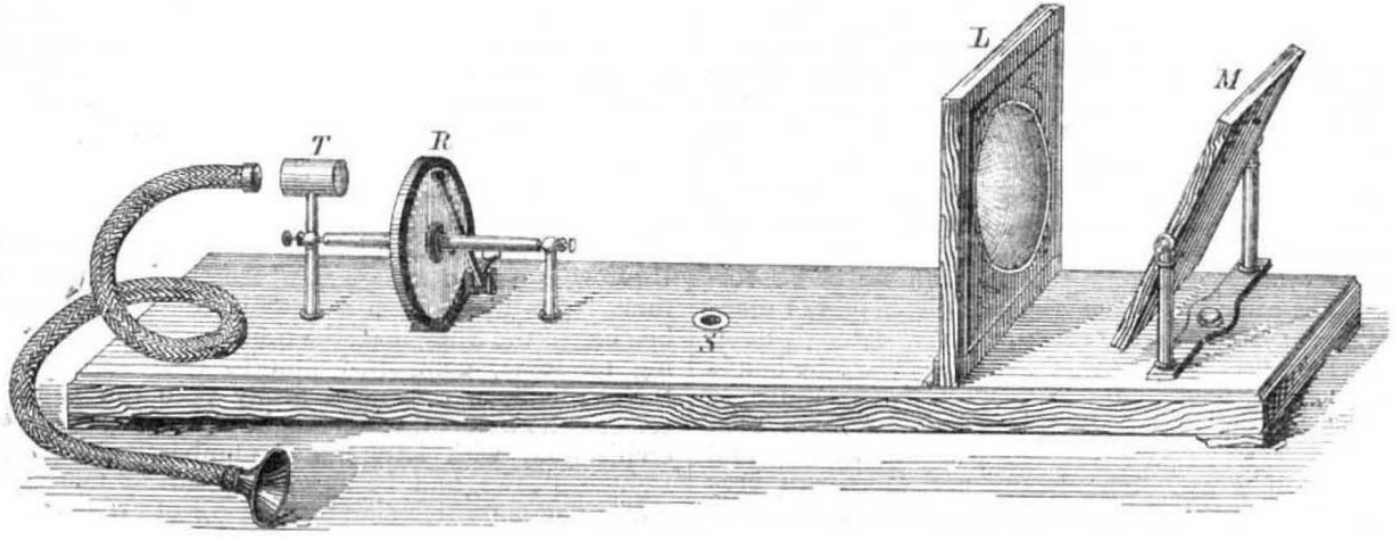

FIG. 1.-The Musical Telephone.

material by merely throwing upon them an intermittent rapid abrupt interruptions of the electric current; while light. Hence in theory, if not in practice, the receiver the articulating telephone of Graham Bell was able to may be reduced to the divine simplicity of a mere disk of transmit speech, since by its essential construction it was

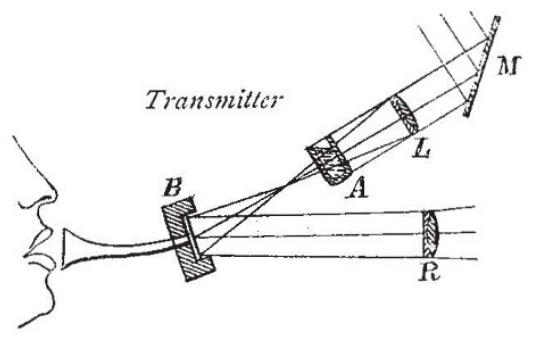

Fig. 2.-Theoretical Diagram of the Articulating Photophone.

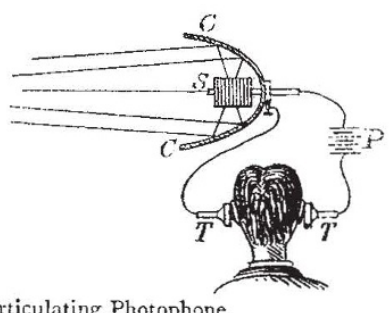

vulcanite or of zinc, on one side of which the vibrating beam of light falls, and at the other side of which the hearer listens.

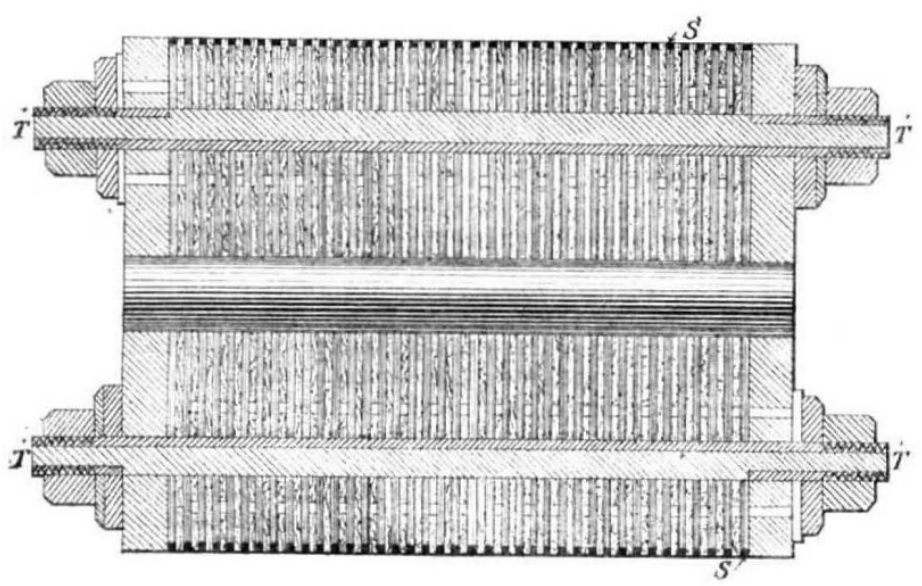

Fig. 3--Section of the Selenium Receiver, shown at $\mathrm{s}$ in Fig. 2 ,

With the photophone, however, as with the telephone, there are instruments of different degrees of perfection. The original imperfect musical telephone of Philip Reis could only transmit musical tones, because it worked by able to send undulating currents to the distant receiving station.

We may in like manner classify the forms of photophone under two heads, as (I) articulating photophones, and (2) musical photophones; the former being able to transmit speech because they work by beams of light whose intensity can vary in undulatory fluctuations, like those of vocal tones; the latter being able to transmit simple musical tones only, since they work by mere interruptions of a fixed bean of light.

Up to the present time, Prof. Bell informs us, the simple receiving disk of ebonite or hard rubber has only served for a musical photophone : the reproduction of the tones of the voice by its means has not yet been demonstrated in practice-at least to his satisfaction. For while it produces unmistakable musical tones by the direct action of an intermittent light, in the experiments made hitherto with articulate speech the instruments have by necessity been so near to one another that the voice of the speaker was audible through the air. Under these circumstances it is extremely difficult to say whether the sounds that are heard proceed from the diaphragm or whether the merely came through the air to the ear, and if they come from the diaphragm, whether they are really the result of the varying light, and not mere sound vibrations taken up by the disk from the speaker's voice crossing the air. Prof. Bell hopes soon to settle this point, however, by an appeal to experiment on a larger scale with the receiving and transmitting instruments at greater distances apart, and with glass windows in between to shut off all sounds.

In Fig. I we illustrate the simple musical photophone of Bell and Tainter. It might perhaps be described without injustice as an optical siren, producing sounds from intermittent beams of light, as the siren of Cagniard
de Latour produces them from intermittent puffs of air. A beam of light from the sun or from a powerful artificial source, such as an electric lamp, falls upon a mirror $M$, and is reflected through a large lens $\mathrm{L}$, which concentrates 
the rays to a focus. Jurst at the focus is interposed a disk pierced with holes-forty or so in number-arranged in a circle. This disk can be rotated so that the light is interrupted from one to five or six hundred times per second. The intermittent beam thus produced is received by a lens $T_{\text {, }}$ or a pair of lenses upon a common support, whose function is to render the beam once more parallel, or to concentrate it upon the disk of ebonite placed immediately behind, but not quite touching them. From the disk a tube conveys the sounds to the ear. We may remind our readers here that this apparent direct conversion of light into sound takes place, as Prof. Bell found, in disks of all kinds of substances-hard rubber, zinc, antimony, selenium, ivory, parchment, wood, and that he has lately found that disks of carbon and of thin glass, which he formerly thought exceptions to this property, do also behave in the same way. We may perhaps remark without impropriety that it is extremely improbable that the apparent conversion of light into sound is by any means a direct process. It is well known that luminiferous rays, when absorbed at the surface of a medium, warm that surface slightly, and must therefore produce physical and molecular actions in its structure. If it can be shown that this warming effect and an intermediate cooling by conduction can go on with such excessive rapidity that beams of light falling on the surface at intervals less than the hundredth of a second apart produce a discontinuous molecular action of alternate expansion and contraction, then the inysterious property of matter revealed by these experiments is accounted for.

However this may be, the musical photophone, as represented in Fig. I, produces very distinct sounds, of whose existence and dependence for their production on the light the listener may satisfy himself by cutting off the light at any moment with the little opaque disk fixed on the end of the little lever just in front of the holes in disk $\mathrm{R}$, and which can be worked by a Morse key like a telegraph instrument, thus producing at will alternate sounds and silences. With this musical photophone sounds have been carried by an interrupted beam of light for a distance exceeding a mile; there appears, indeed, no reason why a much greater range might not be attained.

The articulating photophone is that to which hitherto public attention has been most largely directed, and in which a selenium receiver plays a part. Fig. 2 gives in diagram form the essential parts of this arrangement. A mirror $\mathrm{M}$ reflects a beam of light as before through a lens $\mathrm{L}$, and (if desired for the purpose of experimentally cutting off the heat-rays) through a cell A containing alum-water, and casts it upon the transmitter B. This transmitter, shown again in Fig. 5, consists of a little disk of thin glass, silvered on the front, of about the size of the disk of an ordinary telephone, and mounted in a frame, with a flexible india-rubber tube about sixteen inches long leading to a mouthpiece. A second lens $\mathrm{R}$, interposed in the beam of light after reflection at the little mirror, renders the rays approximately parallel. The general view of the transmitting apparatus given in Fig. 5 enables the relative sizes and positions of the various parts (minus the alum-cell which is omitted) to be seen. The screw adjustments of the support serve to direct the beam of light in the desired direction.

It may be well to explain once for all how the vibra tions of the voice can affect the intensity of the reflected beam far away. The lenses are so adjusted that when the mirror $\mathrm{B}$ is flat (i.e. when not vibrating) the beam projected from the apparatus to the distant station shall be nearly focussed on the receiving instrument. Owing to the optical difficulties of the problem it is impossible that the focussing can be more than approximate. Now, matters being thus arranged, when the speaker's voice is thrown against the disk $\mathrm{B}$ it is set into vibration, becomes alternately bulged out and in, and made slightly convex or concave, the degree of its alteration in form varying with every vibration of the voice. Suppose at any instant - say by a sudden displacement such as takes place when the letter " $\mathrm{T}$ " is sounded-the disk becomes considerably convex; the beam of light will no longer be concentrated upon the receiving instrument, but will cover a much wider area. Of the whole beam, therefore, only a relatively small portion will fall upon the receiving instrument; and it is therefore possible to conceive that, if perfectly adjusted, the illumination should be proportional to the displacement of the disk, and vary therefore with every vibration with the utmost fidelity.

The receiver of the articulating photophone is shown on the right-hand side of the diagram (Fig. 2) sketched by Prof. Bell. A mirror of parabolic curve $\mathrm{C} C$ serves to concentrate the beam and to reflect it down upon the selenium cell $\mathrm{S}$, which is included in the circuit of a battery $\mathrm{P}$ along with a pair of telephones $\mathrm{T}$ and $\mathrm{T}$. Here again a general view like that given in Fig. 6 facilitates the comprehension of the principal parts of the apparatus. The sensitive selenium cell is seen in the hollow of the parabolic mirror which is mounted so as to be turned in any desired direction. The battery standing upon the ground furnishes a current which flows through the selenium cell and through the telephones. When a ray of light falls on the selenium-be it for ever so short an instant-the selenium increases in conductivity, and instantly transmits a larger amount of electricity, and the observer with the telephones hears the ray, or the succession of them;--hears

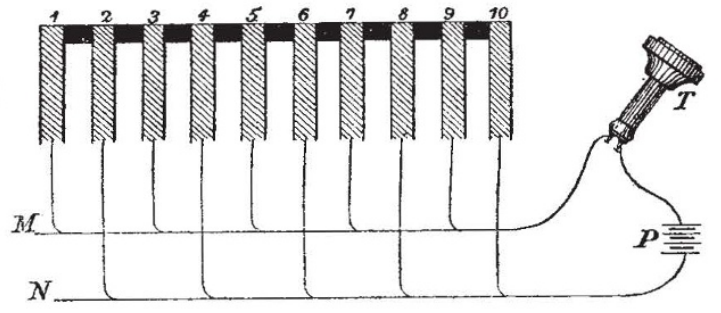

FIG. 4,-Diagran to show the action of the Selenium Receiver.

indeed their every fluctuation in a series of sounds which, since each vibration corresponds to a vibration of the voice of the distant speaker, reproduce the speaker's tones.

The great difficulty to be otercome in the use of selenium as a working substance arose from its very high resistance. To reduce this to the smallest possible quantity, and at the same time to use a sufficiently large surface whereon to receive the beam of light, was the problem to be solved before any practical result could be arrived at. After many preliminary trials with grating and perforated disks of various kinds, Prof. Bell and Mr. Tainter finally settled upon the ingenious device to be described. A number of round brass disks, about two inches in diameter, and a number of mica disks of a diameter slightly less, were piled upon one another so as to form a cylinder about two and a half inches in length. They were clamped together from end to end, the clamping rods also serving to unite the disks of brass electrically in two sets, alternate disks being joined, the Ist, 3rd, 5 th, $\&$ c., being united together, and the 2 nd, 4 th, 6 th, \&c, being united in another series. This done, the edges between the brass disks were next filled with seleninum, which was rubbed in at a temperature sufficiently high to reach the melting-point of selenium. After this the selenium was carefully annealed to bring it into the sensitive crystalline state. Then the cell is placed in a lathe and the superfluous selenium is turned off until the edges of the brass disks are bared. Fig. 3 shows, in section, the construction of such a cell. Prof. Bell has also used cells in which the selenium filled only the alternate spaces between disks, the intermediate spaces being occupied by 
mica disks of equal diameter with the brass disks. But $\mid$ this arrangement was in no way preferable, for in practice

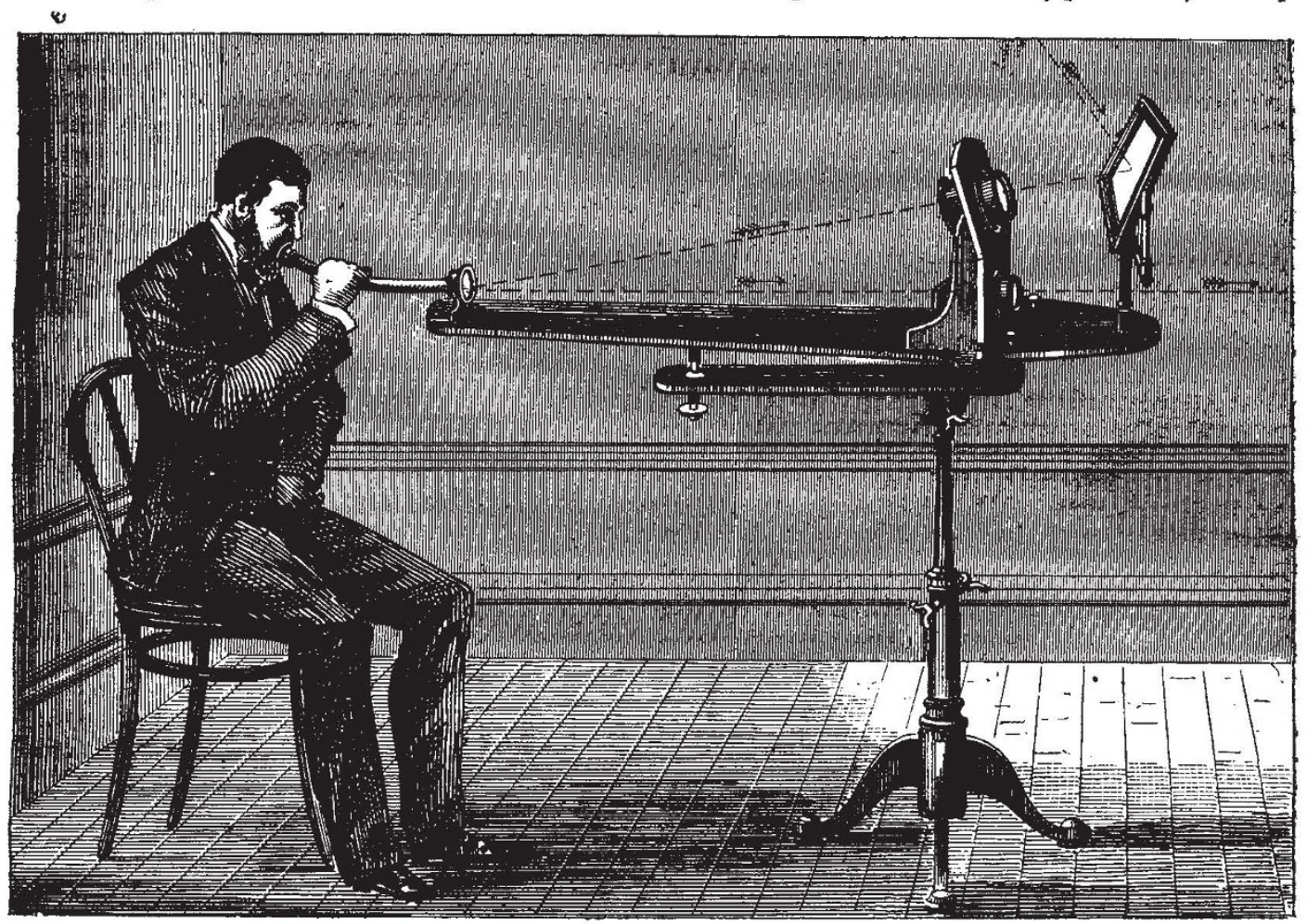

FIG. 5. -The Articulating Photophone. The Transmitter.

it was found that moisture was apt to p:netrate at the $\mid$ Fig. 4 is a diagram which simply illustrates the action surface of the bare mica, spoiling the effest.

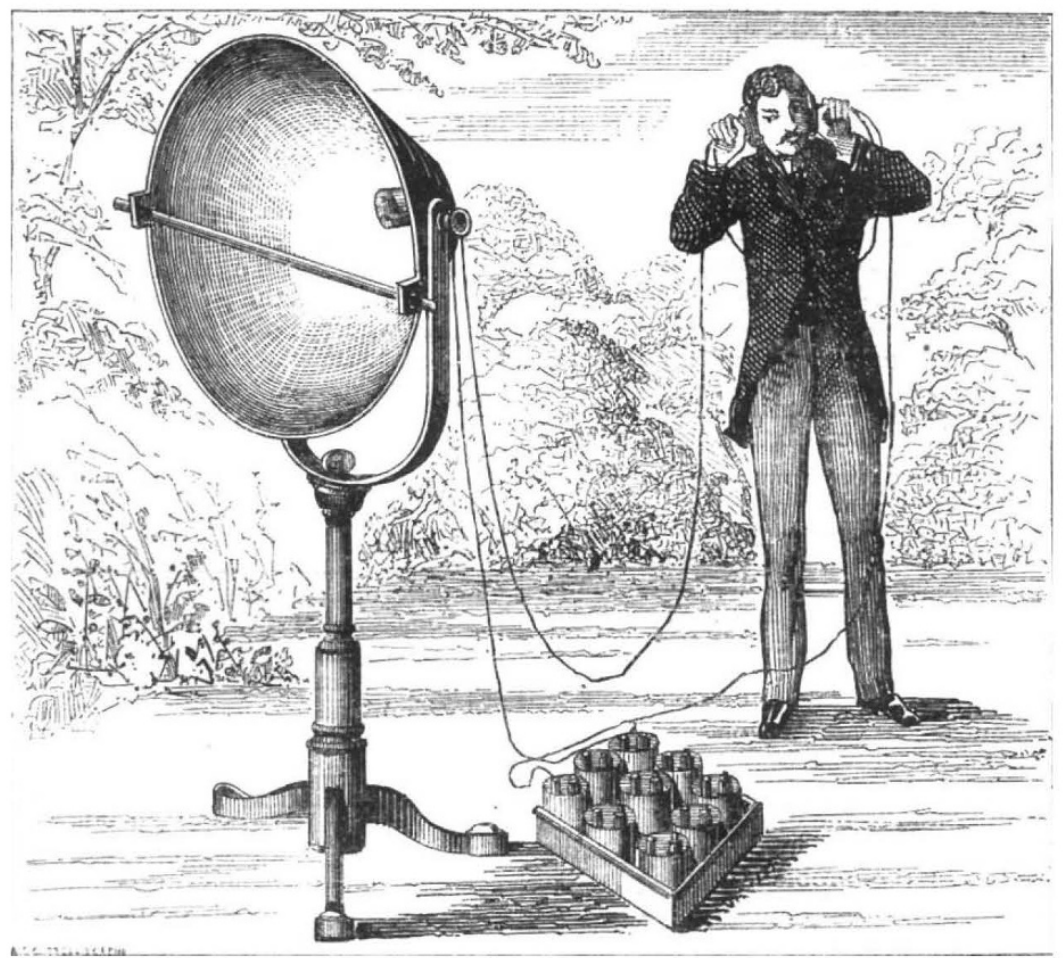

F1G. 6.-The Articulating Photophene. The Selenium Receiver.

connecting the alternate disks; and secondly, that the $\mid$ current from the battery P cannot go round the telephone 
circuit without passing somewhere through selenium from one brass disk to the next. The special advantages of the "cell" devised by Prof. Bell are that in the first place the thickness of the selenium that the current must traverse is nowhere very great; that in the second, this photo-electrical action of light on selenium being atmost entirely a surface action, the arrangement by which all the selenium used is a thin surface film could hardly be improved upon; and that thirdly, the symmetry of the cylindrical cell specially adapts it for use in the parabolic mirror. These details will be of great interest especially to those who desire to repeat for themselves the experimental transmission of sound by light. The greatest distance to which articulate speech has yet been transmitted by the selenium-cell-photophone is 213 metres, or 233 yards.

When sunlight is not available recourse must be had to an artificial source of sufficient power. During the recent experiments made by Prof. Bell in Paris the weather has been adverse, and the electric light has been called into requisition in the ateliers of $M$. Bregnet (Fig. 7, which is kindly supplied us by Prof. Bell). The distance in these experiments between the transmitting diaphragm $\mathrm{B}$ and the parabolic reflector $\mathrm{C} C$ of the receiver was fifteen metres, the entire length of the room in which

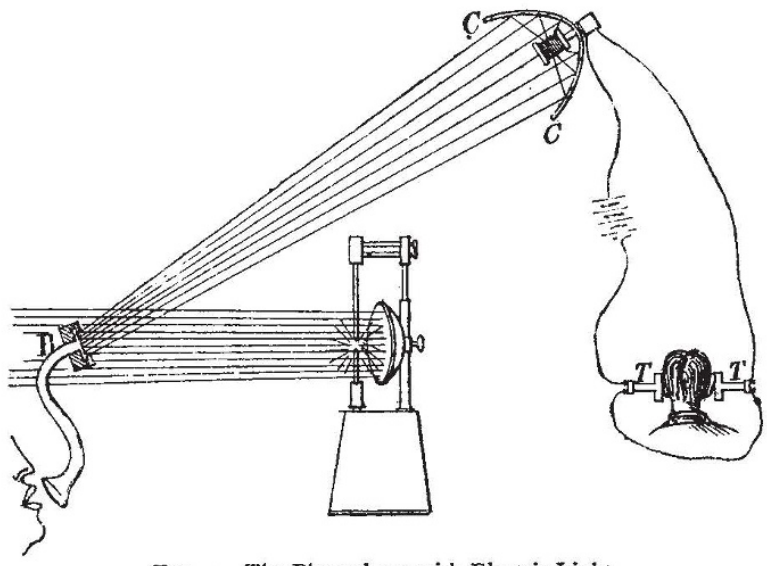

FIG. 7.-The Photophone with Electric Light.

the experiments were made. Since at this distance the spoken words were themselves perfectly audible across the air, the telephones connected with the selenium-cell were placed in another apartment, where the voices were heard without difficulty and without doubt as to the means of transmission.

Of the earlier and less perfect forms of the photophone little need be said. One device, which in Prof. Bell's hands worked very successfully over a distance of eightysix yards, consisted in letting the beam of light pass through a double grating of parallel slits lying close to one another, one of which was fixed, the other movable and attached to a vibrating diaphragm. When these were placed exactly one in front of the other the light could traverse the apparatus, but as the movable grating slid more or less in front of the fixed one more or less of the light was cut off. Speaking to the diaphragm therefore caused vibrations which shut or opened, as it were, a door for the beam of light, and altered its intensity. The mirror transmitter of thin glass silvered was however found superior to all others; and it is hard to see how it could be improved upon, tinless possibly by the use of a thin disk of silver itself accurately surfaced and polished.

Whatever be the future before the photophone, it assuredly deserves to rank in estimation beside the now familiar names of the telephone and the phonograph.

\section{NOTES}

THE Triennial Gold Medal of the Chemical Section of the Philosophical Society of Glasgow, founded in commemoration of the work of Thomas Graham, F.R.S., late Master of the Mint, will be awarded, at the end of the present session, for the best paper on any subject in pure or applied chemistry. Authors are requested to send in their papers not later than February I, I88I, addressed to the Secretary of the Section, Dr. J. J. Dobbie, Chemical Laboratory, University of Glasgow.

THE annual meeting of the five academies which constitute the French Institute was held on Monday last week, when M. E. Levasseur gave an address on the Ethnography of France, and Col. Pcrrier described the operation he undertook to connect geodetically Algeria and Spain.

THE Royal Institution Lecture arrangements (not yet complete) for the ensuing season (before Easter) will include the Christmas course by Prof. Dewar; and courses by Professors Tyndall and Schäfer, the Rev. William Haughton, the Rev. H. R. Haweis, Mr. H. H. Statham, Mr. Reginald S. Poole, and others. Friday Evening Discourses will probably be given by $\mathrm{Mr}$. Warren De La Rue, Prof. Tyndall, Sir John Lubbock, Sir William Thomson, Dr. J. Burdon Sanderson, Dr. Andrew Wilson, Dr. Arthur Schuster, Mr. Alexander Buchan, Dr. W. H. Stone, Dr. W. J. Russell.

THE death is announced of Sir Thomas Bouch, the engineer of the Tay Bridge. It is believed that his system received a severe shock on account of the Tay Bridge disaster and the proceedings consequent on it.

M. ERharD, the well-known French cartographer, died on October 23. M. Erhard was a naturalised Frenchman, having been born at Freiburg-im-Breisgau.

AMONG Mr. Stanford's announcements of forthcoming works are the following :- "Prehistoric Europe: a Geological Sketch," by Dr. James Geikie, F.R.S. ; a fourth edition of "The CoalFields of Great Britain," by Prof. Edward Hull, F.R.S.; "Life and her Children: Glimpses of Animal Life from the Amceba to the Insects," by Arabella B. Buckley; "Index Geographicus Indicus : a Gazetteer of India," by J. F. Barness; "The Flora of Algeria, considered in Relation to the Physical History of the Mediterranean Region and Supposed Submergence of the Sahara," by W. Mathews; "Water Supply of England and Wales: its Geology, Underground Circulation, Surface Distribution, and Statistics," by C. E. de Rance.

IN the November number of Scribner's Monthly is a curious article on Second Sight or Clairvoyance, by an "Ex-Conjuror" (Mr. Henry Hatton), in which it is shown that the whole thing is an elaborate system of mnemonics. The article bas all the appearance of being genuine.

IN reference to the notice in NATURE, vol. xxii. p. 587 , on the address of Dr. Karl Zittel on the subject of the geology of the Libyan Desert, we should state that while the paper contains Zittel's opinions of the observations and collections of other travellers, it is mainly derived from the Professor's personal examination of the physiography of that country, and of the fossils which he there collected, when, as a member of the expedition under the leadership of Dr. Rohlfs, he visited the Libyan Desert in the winter of 1873.74 .

THE lecture on "The Modifications of the External Aspects of Organic Nature produced by Man's Interference," delivered by Prof. Rolleston to the Royal Geographical Society in 1879, has just been published in that Society's Fournal. Amongst other interesting matters Prof. Rolleston rectifies an error into which all or most translators of Cæesar have fallen respecting 